\title{
Design and Analysis of Elevator based on Intelligent Control System
}

\author{
Jin Yao
}

School Department of mechanics and materials engineering, Wuzhou University, Wuzhou 543000, China

Keywords: Permanent magnet synchronous motor; Fuzzy PI control; Elevator.

\begin{abstract}
In order to achieve high-performance control for permanent magnet synchronous motor, using intelligent control strategies, mainly fuzzy control and fuzzy neural network control, using Mat lab/Simulink toolbox designed fuzzy controller based on fuzzy PMSM Vector Control system simulation analysis, simulation results show that the system has good dynamic performance and robustness.
\end{abstract}

\section{Introduction}

Software design of this paper includes application development and driver development in two ways. For application developers in this area, this article will lift a thorough understanding of the actual works, in-depth study designed for embedded systems applications, on this basis, the preparation procedures, implement basic logic functions intelligent elevator core controller.

\section{Intelligence Research elevator scheduling algorithm}

Control issues discussed in this article elevator controller has its unique complexity, elevator control problems sub-period, the partition segment, sub-targets was considered likely to make the most suitable for the actual operation of the planning schedule, ${ }^{[1-5]}$ and on this basis, but also taking into account factors such as energy conservation. Constitute the general mathematical model of multi-objective optimization problem, the first decision variable, followed by an objective function, and finally constraints. Suppose the following multi-objective decision problem. Their decision variables $n$, $m$ constraint conditions:

$$
g(x)=\left(g_{1}(x), g_{2}(x), \ldots, g_{m}(x)\right)^{T} \geq 0
$$

Objective functions $\mathrm{P}$ :

$$
f(x)=\left(f_{1}(x), f_{2}(x), \ldots, f_{p}(x)\right)^{T} \geq 0
$$

Calculate the optimal solution, denoted by:

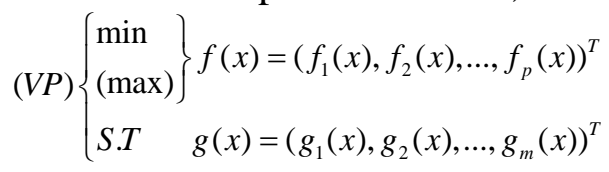

If:

$$
R=\left\{x \in E^{n} \mid g(x)=\left(g_{1}(x), g_{2}(x), L, g_{m}(x)\right)^{T} \geq 0\right\}
$$

The (VP) becomes:

$$
V P\left(\max _{x \in R}\right) f(x)=\left(f_{1}(x), f_{2}(x), L, f_{p}(x)\right)^{T}
$$

VP is the formula established in the form of multi-objective planning. Control field, each unit control needs may be different, which requires us to control demand before this standardization. Here is the normalization process, so that:

$$
f_{i}(x)=\bar{f}_{i}(x) / \bar{f}_{i}
$$

These functions have inextricably linked to each other, these links some positive, some reverse, which determines the merits of this issue cannot achieve the most absolute sense, it will certainly 
satisfy certain conditions in terms of the lack of, but coordinated as a whole, it can basically meet all the conditions to obtain a holistic solution.

\section{Scheduling algorithm model elevator controller}

Each time a passenger spends waiting on the elevator are different, which may be related to the passenger floor itself, which is also possible with the time he reached the point of issuing a call about the floor, but not unpredictable. ${ }^{[6-8]}$ whether running speed or passenger elevator and out of time, also, or other relevant information, the state, can be estimated on the waiting time. For different groups of passengers we cannot strictly in accordance with the principle of fairness to calculate the waiting time, where we select the average as a control parameter, which is composed of two parts, the part of the elevator running time, the other part is the elevator stops time:

$$
\begin{aligned}
A W T(i) & =T_{\text {run }}(i)+T_{\text {stop }}(i) \\
& =T_{r} * N_{r}(i)+T_{s} * N_{s}(i)
\end{aligned}
$$

Similarly with the average waiting time, average riding time can still be relevant amount of time with a few pre-estimate of the above, we used to indicate that it includes an elevator and the elevator stops time running time:

$$
A R T(i)=T_{r u n}^{\prime}(i)+T_{\text {stop }}^{\prime}(i)
$$

Passengers riding time, the same rate through the elevator door switch time, and out of the number of passengers, the election means the signal status and external call signal status assigned to expect. However, due to the current situation calls for the allocation of floor elevator to arrive before had no material impact to reach that part of the floor of the guests to their needs, so the function discussed here to use the elevator to reach the floor until after the next portion of the elevator time to take the elevator passengers were characterized. This section consists of two time components, a landing when the station after work over a long elevator and the elevator landing stay long:

$$
A R T(i)=T_{r} * N_{r}^{\prime}(i)+T_{s}^{*} N_{s}^{\prime}(i)
$$

The congestion level evaluation function of the car: The congestion degree of the car can be used in the volume ratio of the number of passengers in the car and the car is represented.

$$
G R D(i)=\frac{Q(i)}{Q_{\max }}
$$

The system energy consumption evaluation function: In the elevator running, start and stop the acceleration phase deceleration phase will have greater energy consumption, and therefore should be run with less frequency to carry more passengers, making stops to minimize the number of elevators, reducing lift energy consumption. Where energy consumption is represented by start and stop the elevator stops and starts during startup energy consumption, energy consumption reduction, open and closed consumption of energy and, while the energy consumption of an elevator with a run through a floor of uniform closed energy consumption and so on.

$$
\operatorname{ERC}(i)=C_{s t} * N_{s}(i)+C_{r} * N_{r}(i)
$$

Reduce the energy consumption of an elevator system another point is to reduce the lift stroke by reducing runtime, thereby reducing power consumption. In addition, the lift-load upstream, downstream motor full load renewable electricity generation in the state, in the high-speed elevator system can be regenerated energy back to the grid. With this feature, the group control system can summon signal priority allocation in the above running elevators for landing, to save energy.

\section{Elevator control experiments using permanent magnet synchronous motor intelligence}

This paper assumes permanent magnet synchronous motor parameters: stator winding itself brought ohm resistor $\mathrm{R}=0.618$ straight axis inductance parameter values for $\mathrm{L}=0.007418 \mathrm{H}$, numerical quadrature axis inductance parameters for $\mathrm{L}=0.012285 \mathrm{H}$, rotor flux parameter values for $\psi=$ $0.1128 \mathrm{~Wb}$, the number of pole pairs is the number of $\mathrm{p}=2$. In this paper, the response shown in 
Figure 1 and Figure 2, can be concluded from the figure, hysteresis current tracking control parameters and the voltage space vector control mode speed response parameters obtained through experiments in two speed motor control mode are to meet modern society rapidity and stability of the elevator requirement.
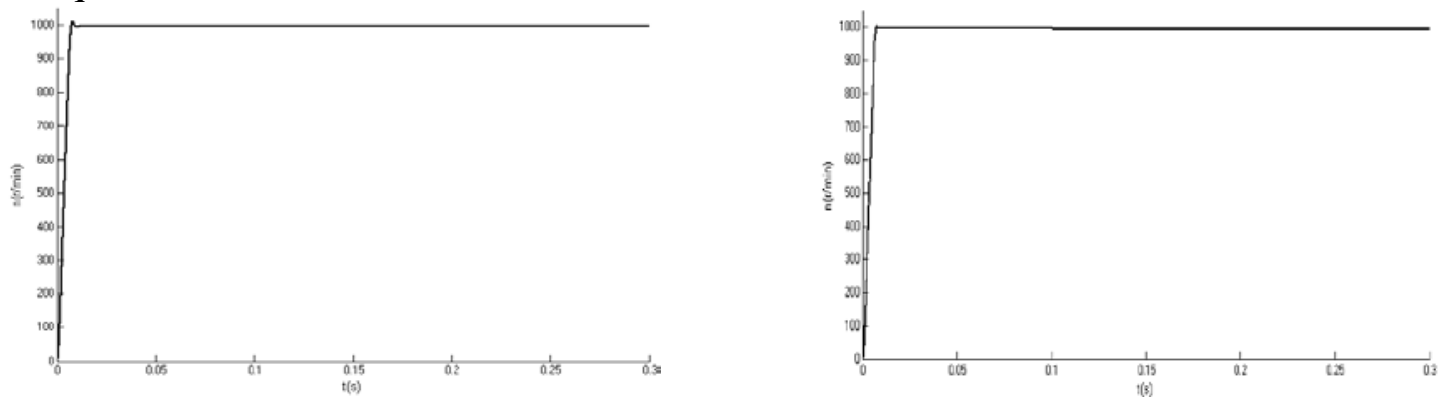

Fig.1 Hysteresis current control response speed Fig.2 Voltage space vector control speed response

This article will get the next two control methods using electromagnetic torque response results in Figures 3 and 4 show the voltage space vector control parameters of the electromagnetic torque pulsation amplitude response of a stable and fixed switching frequency. Hysteresis current tracking control parameters than the voltage space vector control parameters of the electromagnetic torque response of poor quality, this article is from the pulsating oscillation amplitude is large and volatile aspects of discovery. The higher the frequency of the circuit leads to higher switching losses resulting in circuit efficiency and reduce the power factor decreases.

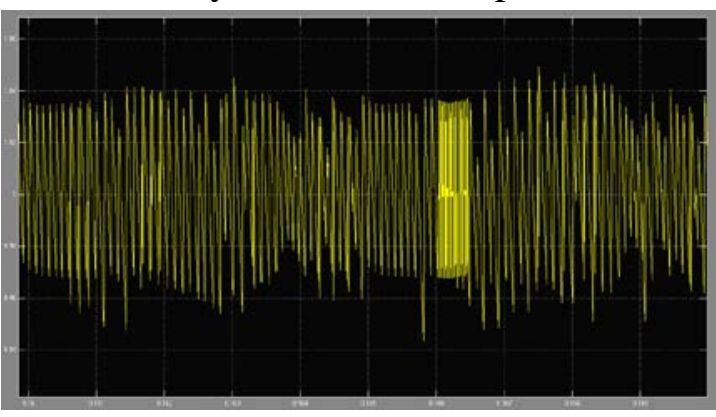

Fig.3 Hysteresis current tracking control of electromagnetic torque response of local

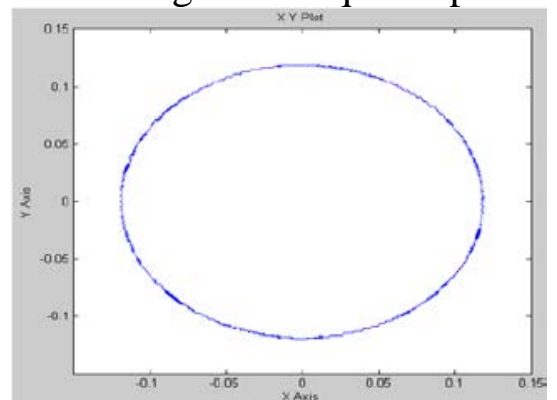

Fig.5 Hysteresis current tracking control flux

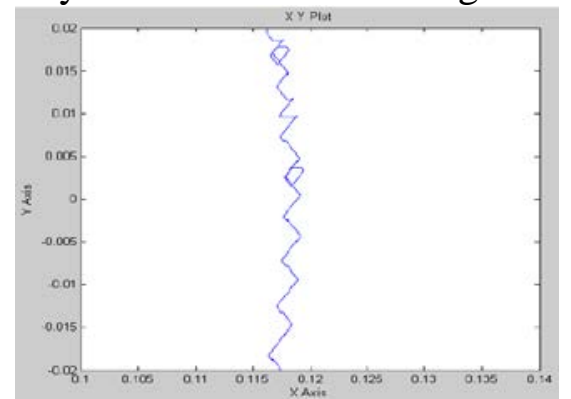

Fig.7 Hysteresis current tracking control flux local Fig.8 Voltage space vector control flux local This article obtained from the two control modes Flux response waveform in Figure 5, Figure 6, Figure 7 and Figure 8, the current hysteresis parameter tracking worse than the magnetic chain quality control voltage space vector control parameters formed, mainly large peaks and valleys in the
Fig.4 Voltage space vector control of electromagnetic torque response of local

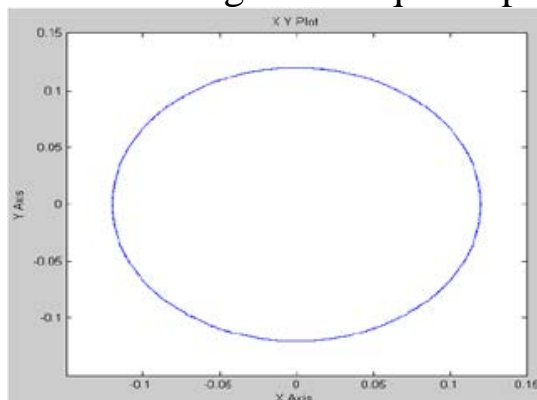

Fig.6 Voltage space vector control flux

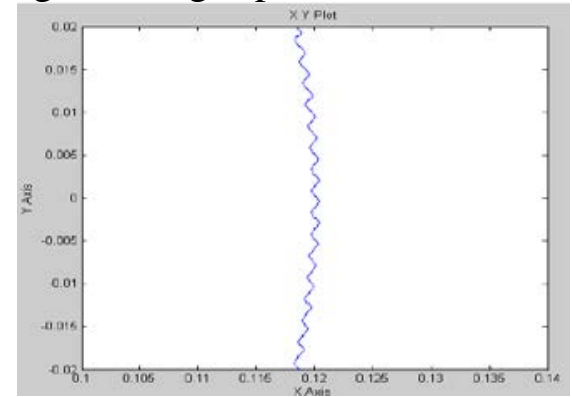

Fig.8 Voltage space vector control flux local
lux response waveform in Figure 5, Figure 6,
eter tracking worse than the magnetic chain
formed, mainly large peaks and valleys in the 
pulsating waveform does not meet the normal rules no cycle, while the flux voltage space vector control parameters to be significantly currency flux hysteresis current tracking control parameters much better.

\section{Summary}

This paper established a mathematical model of permanent magnet synchronous motor, and its detailed analysis, the matrix is derived by linear algebra and validated flux permanent magnet synchronous motor observability, using simulation tools is now more popular Matlab / Simulink to build the current hysteresis characteristic parameter tracking control and voltage space vector control simulation model parameters and the way these two inverters to be a detailed comparison. In this thesis research is used in modern mainstream elevator permanent magnet synchronous motor electric drive system, the paper selected inverter voltage space vector modulation control.

\section{References}

[1] Thomas M. Jahns, Motion Control with Permanent-Magnet AC Machines[C]. Proceedings of the IEEE, Vo1.82 No.80, August 2012: p.41-45.

[2] Joohn Sheok Kim, Seung Ki Sul. New approach for high performance PMSM drives without rotational position sensors[C]. IEEE APEC' 2011: p.381-386

[3] Dhaouadi R, Mohan N. Design and implementation of an extended kalinan filter for the state estimation of a permanent magnet synchronous motor[C]. IEEE Trans. on EPE. 2009, 6 (3): p. 491-497

[4] M. N. Uddin and M. A. Rahman. Fuzzy Logic Based Speed Control of an IPM Synchronous Motor Drive[C]. Proceedings of the 1999 IEEE Canadian Conference on Electrical and Computer Engineering Shaw Conference Center, Edmonton, Alberta, Canada May 9-12 2009:p. 41-45

[5] Wu R, Slemon G.R. A permanent magnet motor drive without a shaft sensor[C]. Conference of Record IEEE IAS Annual Meeting, 2010: p.553-558

[6] Eriugrul N, Acarnley P.P, A new algorithm for sensor less operation of permanent magnet motors[C].IEEE Trans. on IA.1992, 30(1): p.126-133

[7] Bado A, Bolognani S. Effective estimation of speed and rotor position of a: PM synchronous motor drive a kalman filtering technique [C]. IEEE PESC' 2012: p.951-95.

[8] Ueda R, Ta kata H. On the estimation of transient state of power system by discrete nonlinear observer[C]. IEEE Trans. PAS. 2005(6): p.2135-2140. 